\title{
Microstructure of Thermoplastic Composites Reinforced with Wool and Wood
}

\author{
C. Baptista ${ }^{a^{*}}$, G. Martins ${ }^{b^{*}}$, C. Santos ${ }^{a}$, A. Mateus ${ }^{a}$ and F. Antunes ${ }^{b}$ \\ ${ }^{a}$ Centre for Rapid and Sustainable Product Development, Polytechnic Institute of Leiria, 2430-028 \\ Marinha Grande, Portugal \\ bDepartment of Chemistry, University of Coimbra, 3004-535 Coimbra, Portugal \\ "Corresponding authors: catarina.baptista@ipleiria.pt and agtmartins@gmail.com
}

Keywords: Wool, wood, fibres, thermoplastic, composite, microstructure.

\begin{abstract}
In the last decades the studies on thermoplastic composites reinforced with natural fibres have been mostly focused on vegetable lignocellulosic or cellulosic fibres. These materials provide eco-sustainable solutions for a large range of applications and have been actually adopted by multiple industries. The interest on fibres of animal origin is more recent and research on composites reinforced with these fibres predominantly composed of keratin, such as wool, feathers or silk, is increasing in virtue of some advantageous properties that may overcome some of the intrinsic limitations from vegetable fibres. The combined use of vegetable and animal fibres in composites appropriate for melt blending processing is at early stages of research. After chemical treatments, the fibres of animal origin have been mostly applied as binders between vegetable fibres and polymers, but not as main constituents of these composites.

The use of both types of fibres simultaneously in composites of thermoplastic matrices is the subject of the present study where the fibres of animal origin (wool) are sourced from different kinds of residues from a textile industry and the fibres of vegetable origin (wood) are the residues from carpentry activities. The chemical composition, the macro and microstructure of the fibres is analyzed, as well as that of the composites that combine non-biodegradable and biodegradable polymers with diverse ratios of the fibres in different conditions (wool as cards, yarns and felt cloths; wood as sawdust). The addition of coupling agents to enhance the compatibility between wool, wood and different polymers is also analysed.
\end{abstract}

\section{Introduction}

In 1950, when plastic was first mass produced, the manufactured amount was around 2 million tonnes. That figure has risen to 8.3 billion tonnes in 2017 and is projected to reach 34 billion tonnes by 2050 . In these decades, the number and type of industries that have been processing plastic materials has greatly increased and the end products constitute, in the vast majority, items with a very short lifetime compared to other man-made materials and products. The plastic production, which is mostly based on polymerization of monomers from fossil hydrocarbons, has been driven largely by packaging industries and others, responding to global changes in civilization. The rise of single-use containers, wrapping and bottles constitute paradigmatic examples of the increase, worldwide and day-after-day, of the generated plastic wastes. Recent studies estimate that half of all plastics become waste after four or fewer years $[1,2]$.

The impact of plastics in the world is a serious matter of concern in virtue of the increasing pollution they cause, threatening a near permanent contamination of the natural environment, whether it occurs in land, reaching the rivers and the seas, or directly in the oceans. It has been estimated that in 2015, the plastic production reached 380 million tonnes and the amount of plastic wastes in the world was around 7 billion tons, $79 \%$ of which were deposited in landfills, drained to sewage plants, or simply accumulated in nature, $12 \%$ were incinerated and $8 \%$ recycled. In 2017 , the plastic wastes have increased to over 8 billion tons. These statistics do not include bio-based or biodegradable plastics (production of 4 million tonnes in 2015) because these constitute a minor 
fraction, near $10 \%$ of the current global production capacity. It includes thermoplastics, thermosets, polyurethanes (PURs), elastomers, coatings, and sealants, but focuses on the most prevalent resins and synthetic fibres: high density polyethylene (PE), low-density and linear low-density PE, polypropylene (PP), polystyrene (PS), polyvinylchloride (PVC), polyethylene terephthalate (PET), and PUR resins; and polyester, polyamide, and acrylic (PP\&A) fibres [1]. None of these are biodegradable and their wastes require thermal treatments (as combustion or pyrolysis) to be permanently eliminated.

In this context, any strategy leading to the decrease or replacement of plastic materials and products may be of great significance. The use of composite materials of polymeric matrix reinforced with natural fibres that may be processed with the same technologies of the conventional plastics, is gaining increasing interest though the concept is no longer new. It emerged decades ago, in the 1960's. The earlier composites that found many applications and reached the market easily were the wood plastic composites (WPC), based on wood and thermoplastic or thermoset polymers [3-6]. While the former type may be recycled due to the reversibility of the thermal behaviour of the matrix, the latter cannot. Additionally, the technical options for thermoplastic materials are much wider and the possible applications reach as many industries as those of the conventional plastics [4,7-10].

The use of natural fibres, particularly of vegetable origin, as a reinforcement in composites of thermoplastic matrices has been increasing considerably through time and the number of vegetable species has also grown [5,6,11-19]. In large part, this is due to some superior advantages and specific properties of these fibres compared to the synthetic ones, such as carbon or glass fibres. Besides allowing the reduction of petroleum derived materials, the natural fibres are renewable and biodegradable materials that present low density, low cost and mechanical properties favourable to several applications. Both their processing in composite materials and the subsequent manufacture of end products are relatively low energy consumption operations which normally do not cause friction damage to the equipments, nor cause harmful emissions. The processing technology for the synthesis of these composites is based in melt blending, most often extrusion. The subsequent applications determine the selection of techniques and operative conditions. As examples, some products may be manufactured by extrusion such as rafters and other profiles used in civil construction $[8,12,13,19-22]$. Other products, as certain automobile components of low or medium load capacity, are produced by injection molding [5,6,11-19]. Currently, the list of automobile manufacturers using composite components is quite extensive, being common materials in door panels, dashboard areas or seats in several well-known brand models [8-10,23-29].

The obtained products typically have a high specific (per unit mass) strength, good surface finish and reduced dimensional variation. However, this type of composite materials also presents some problems and limitations. The vegetable fibres are mostly composed of cellulose (and also hemicellulose) and their degradation with temperature typically starts around $200{ }^{\circ} \mathrm{C}$ (or less). In order to obtain a composite material, the fibres cannot be combined with polymers that melt at temperatures superior to that value. In case of using wood, since it also contains lignin that degrades at temperatures slightly higher than cellulose, the processing temperature of the composite admits a polymer with a melting point some degrees higher than that used with simple cellulosic materials. This means that the type of fibres limits the selection of adequate polymers concerning their thermal properties. Another important limitation is the compatibility between materials with different character. Typically, whereas the vegetable fibres are hydrophilic, the polymers are hydrophobic. Unless an adequate coupling agent (or binder) is used, the mechanical properties of the composites may be compromised. The coupling agents are frequently polymers that are miscible with the matrix and chemically modified by grafting functional groups (as maleic anhydride or acrylic acid) [14,23,30-33]. These react with hydroxyl groups from the cellulosic components of the fibres. This method enables the formation of chemical bonds between the fibres and the mixed polymeric matrix, promoting the interfacial adhesion, decreasing defects as porosity and increasing the density and tensile strength of the composite, among other properties. The good surface finish enabled by these composites has also fostered, for instance, the production of parts applied in certain dynamical 
systems of the automobile that require a specific tribological behavior. Other procedures such as surface modification of the fibres are also frequently applied [14,23,34-37].

The use of fibres of animal origin in equivalent composite materials is much more recent. The scientific research about this subject has included mostly wool, feathers and silk, being all these fibres mainly composed of proteins [38-41]. Diverse motivations can be found, from the reuse and recycling of wastes of different raw materials to more specific reasons, focused on the material properties of these fibres and on the possibility of obtaining composites with interesting and useful properties [7-9,13,39,41-44]. Briefly, comparing to vegetable fibres, those of animal origin are typically less hydrophilic and more resistant to temperature degradation, including the ability to prevent the spread of fire. Although these properties allow to obtain better interfacial adhesion between components, the addition of coupling agents similarly to those applied with cellulosic fibres has provided enhanced properties in some study cases. Plus, the thermal behaviour of the animal fibres opens the possibility of combining them with polymers of higher melting points than those used with vegetable fibres. These general properties need to be specified for each type of fibre and also relate to the preliminary treatments that they are usually submitted to [44-46].

Wool, in a generic approach, owes its properties not only to the chemical composition, but also to the macro and microstructure of the fibres. Wool can be obtained from diverse animals and the properties of the fibres depend on the species. In spite of this variation, some general statements can be made. The clean wool belongs to a group of proteins called keratins, constituted by specific sequences of amino acids. It is estimated that wool contains more than 170 different proteins, heterogeneously distributed along the fibres. This heterogeneous composition is responsible for different physical and chemical properties in various regions of the fibres [39,44-46]. Typically, these fibres have variable lengths and thickness of a few micrometers. Their structure may be organized in three main components: the medulla, the cortex and the outer layer, the cuticle, which is covered with scales and naturally coated by a greasy layer (lanolin) that helps water repellency. Even after removing the natural wool fat by washing with detergent, wool fibres are more difficult to wet compared to other textile fibres. This natural hydrophobicity renders wool as "waterproof". At the same time, the porosity of the cortex enables the absorption of gaseous water, being also responsible for the success of dyeing the fibres for textile applications $[40,42,45]$.The first step in the processing of wool, regardless of the intended final product, is to wash it with hot water and gentle saponification agents to remove dirt, fat and other impurities. This washing is usually carried out at $65^{\circ} \mathrm{C}$, which is insufficient to dissolve the wax (e.g. lanolin). The detergent is added to remove the impurities and emulsify the waxes so that the fibres do not stick together. Clean wool contains $82 \%$ keratinous proteins that contain by high sulfuric concentrations. The strength of the wool fibres is due to strong disulphide bonds. Keratin is not soluble in cold or hot water and does not degrade in soluble substances [44-46]. As mentioned, the surface of the fibres consists of a cuticle coated with multiple scales. Some wool treatments cause the irreversible interlock between the scales of adjacent fibres and when applied to textile fabrics under controlled conditions, these may shrink as much as 50\% in all directions, originating a dense and continuous material [45]. This process is referred to as felting and illustrates the importance of the treatments given to these fibres in their final properties. On this matter, it is very important to consider the fact that the wool processing methods are complex procedures, from its origin until the final products, and these steps that must also be considered since they influence the fibres properties. Moreover, the wool fibres may be used in multiple conditions, even after being transformed in textile fabrics.

The synthesis, processing methods and applications of composites reinforced with wool fibres are not very different from those with vegetable fibres. The material properties of the composites may be modulated by changing parameters or conditions as fibre length, pre-treatments, use of coupling agents or other additives. On the other hand, the combined use of animal and vegetable fibres, both with reinforcement value in the same polymeric matrix, is very rare. The exception comes from taking advantage of the wool's character of dual capacity of interaction with water, 
transposed to the application of the chemically treated animal fibres to composites reinforced with vegetable fibres, with the function of binder or coupling agent [9,10,47-51].

The present study reports the simultaneous use of wool and wood, both in the form of diverse industrial wastes, to synthesize thermoplastic composites adequate for processing by extrusion, injection molding or other techniques based in melt blending. It describes some of the preliminary studies required to achieve, in following studies, a selection of raw materials that fulfils predetermined conditions that will influence the optimization of the composites composition, their thermal properties (including adequate viscosity for processing), mechanical properties and surface characteristics. This study is focused in the chemical composition of the fibres and polymers (matrix and coupling agents), and in the structural characterization of the different fibres and of several composites of non-biodegradable and biodegradable polymers, both at macro and microscopic levels.

\section{Experimental}

Materials. Wool fibres - the wool samples were supplied by a textile industry (Burelfactory, Manteigas, Portugal) that processes the raw wool from autochthon sheep, from the carding process to the preparation of yarns with variable number of strands, until the weaving of fabrics, particularly of cloths obtained by felting procedures. Different classes of residues were supplied and these were named, in this study, after their origin: the cards correspond to the remaining fibres after carding, the yarns correspond to the wastes from the bobbins, and the felt cloths correspond to wastes from the finished products. The cards were pulled by hand from the bulk, the yarns were cut to lengths of $5-10 \mathrm{~mm}$ and the felt cloths were cut to areas of around $2 \mathrm{~mm} \times 20 \mathrm{~mm}$ ). The cards presented the colour of raw wool and the yarns and cloths presented diverse colours.

Wood particles - the wood samples were supplied by a carpentry industry (Valco, Leiria, Portugal) and corresponded to pine sawdust with mixed mesh sizes. The sawdust was dried at $80{ }^{\circ} \mathrm{C}$ until constant weight and after sieving to different size ranges, the particles were classified as Fine (inferior to $0.7 \mathrm{~mm}$ ), Medium (between 0.7 and $1.4 \mathrm{~mm}$ ), Coarse (between 1.4 and $2.8 \mathrm{~mm}$ ) and Extra (superior to $2.8 \mathrm{~mm}$ ). The sieved particles from two batches were weighted to determine the particle size distribution of samples supplied at different times.

Polymers - Four synthetic non-biodegradable thermoplastics, appropriate for injection molding, were acquired to industrial suppliers, being 2 of these used as composite matrices and the other 2 as coupling agents. The matrix polymers were high density polyethylene (HDPE) 10100 UE from Dow Chemicals and polypropylene (PP) $1100 \mathrm{~N}$ from Ducor Petrochemicals. The coupling agents were copolymers of polyethylene and ethylene vinyl acetate grafted with maleic anhydride, PE-co-MA (Fusabond E-226) and EVA-co-MA (Fusabond C-190), from Dupond. Some technical data ( $d=$ density, $H D T=$ heat deflection temperature, $\mathrm{T}_{\mathrm{m}}=$ melting temperature, $\mathrm{MFR}=$ melt flow rate (in standard tests with $2.16 \mathrm{Kg}$ at $190{ }^{\circ} \mathrm{C}$ ), $\sigma_{\mathrm{y}}=$ tensile stress at yield) from the producers are presented in Table 1.

Table 1 - Synthetic polymers used in this study: some thermal and mechanical properties from the respective Product Data Sheets.

\begin{tabular}{lllllll}
\hline Polymer & Reference & $\mathrm{d}\left(\mathrm{g} / \mathrm{cm}^{3}\right)$ & HDT $\left({ }^{\circ} \mathrm{C}\right)$ & $\mathrm{T}_{\mathrm{m}}\left({ }^{\circ} \mathrm{C}\right)$ & $\mathrm{MFR}(\mathrm{g} / 10 \mathrm{~min})$ & $\sigma_{\mathrm{y}}(\mathrm{MPa})$ \\
\hline HDPE & KS $10100 \mathrm{UE}$ & 0.95 & $128($ Vicat $)$ & - & 4 & 25 \\
PP & $1100 \mathrm{~N}$ & 0.91 & 154 (Vicat $)$ & 163 & 12 & 35 \\
PE-co-MA & E-226 & 0.93 & 95 & 120 & 1.75 & - \\
EVA-co-MA & $\mathrm{C}-1905$ & 0.95 & - & 71 & 16 & - \\
\hline
\end{tabular}

A biopolymer of experimental value, based on potato starch and hence biodegradable, was supplied by United Resins, Figueira da Foz, Portugal. Its data sheet was not available.

All polymers were in pellet form. To eliminate any moisture and prevent thermal transitions, the polymers were dried at $50^{\circ} \mathrm{C}$ before being used. 
Instrumental techniques. FTIR analysis. The vibrational spectra from Fourier Transform Infrared Spectroscopy (FTIR) were obtained using a Nicolet Magna IR-750 spectrometer (Nicolet, Madison, WI, USA) in the attenuated total reflection (ATR) mode. The spectra were registered in the $500-4000 \mathrm{~cm}^{-1}$ region using 64 scans and a spectral resolution of $2 \mathrm{~cm}^{-1}$. FTIR spectroscopy was used mainly to provide a qualitative analysis of the chemical composition of the samples.

$\underline{S E M}$. Scanning Electron Microscopy (SEM) observations were carried out in a Philips XL30 microscope (Philips, Amsterdam, Netherlands) operating at 2.0 KV. The samples prepared for SEM analysis were 3 kinds of wool fibres (cards, yarns and felt cloths), Fine wood particles and composites of diverse chemical compositions. The composites were immersed in liquid nitrogen and subsequently fractured so as to expose the interior section without deformations from cutting tools. The samples were coated with a thin layer of gold by plasma sputtering during 5 to 10 seconds.

Synthesis of composites. The composites were prepared in a Brabender Plastograph mixer of $55 \mathrm{~cm}^{3}$, equipped with Torque and temperature measurements. The blends were prepared at $60 \mathrm{rpm}$ and $80-180{ }^{\circ} \mathrm{C}$, depending on the selected polymers. The method used in the synthesis of the composites involved monitoring the viscosity through the blending of the components, starting with melting the polymer of the matrix together with the coupling agent. Then, after the torque was stable, the selected fibres were added (first the wool and then the wood, or the opposite) always letting the torque stabilize between each addition. The obtained melted composites were removed from the mixing chamber after the viscosity was stable for five minutes following the last fibres addition and let at room temperature until solid state was achieved. The relative amounts of each composite component are not revealed in this report.

\section{Results}

Macrostructure of the wool fibres and of the wood particles. The global appearance of the wool fibres that constitute residues from a textile industry is presented in Fig. 1: cards (A), yarns (B) and felt cloths (C). The cards are very compact and mixed fibres of variable lengths, with moderately homogeneous colour. The yards are notoriously from different bobbins and their length can reach several meters. The yards are made of variable number of spinned strands and have different thickness, colour and smoothness. The separation of the yarns has to be made by hand. The felt cloths are very dense, single colour fabrics (yellow, red, green, blue, violet, white, ...) with large dimensions. Their area can reach $1 \mathrm{~m}^{2}$ and their thickness is around $2 \mathrm{~mm}$. These cloths must be cut for further use.

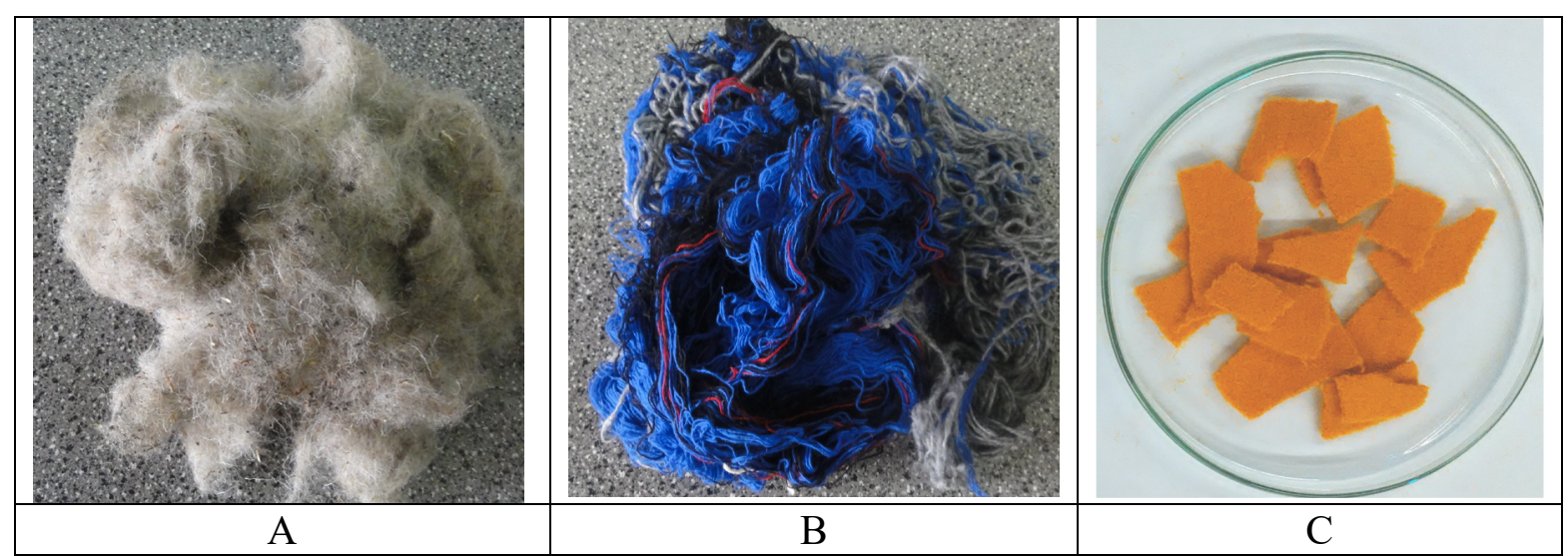

Figure 1 - Wool fibres from textile industrial residues: cards (A), yarns (B) and felt cloths (C).

In order to prepare blends of thermoplastics with the different wool fibres, these have to be separated and/or cut into smaller fibres. The fibres length is a key factor in the mechanical properties of the composites but this variable is not under analysis in this study. Nevertheless, the 
general appearance of the fibres, as they were used, is presented in Fig. 2. The cards were pulled from the bulk by hand, the yards were cut into 5-10 $\mathrm{mm}$ and the felt cloths were cut to areas around $2 \mathrm{~mm} \times 20 \mathrm{~mm}$. This figure also shows a falcon containing polymer pellets and its dimension can be used as reference scale.

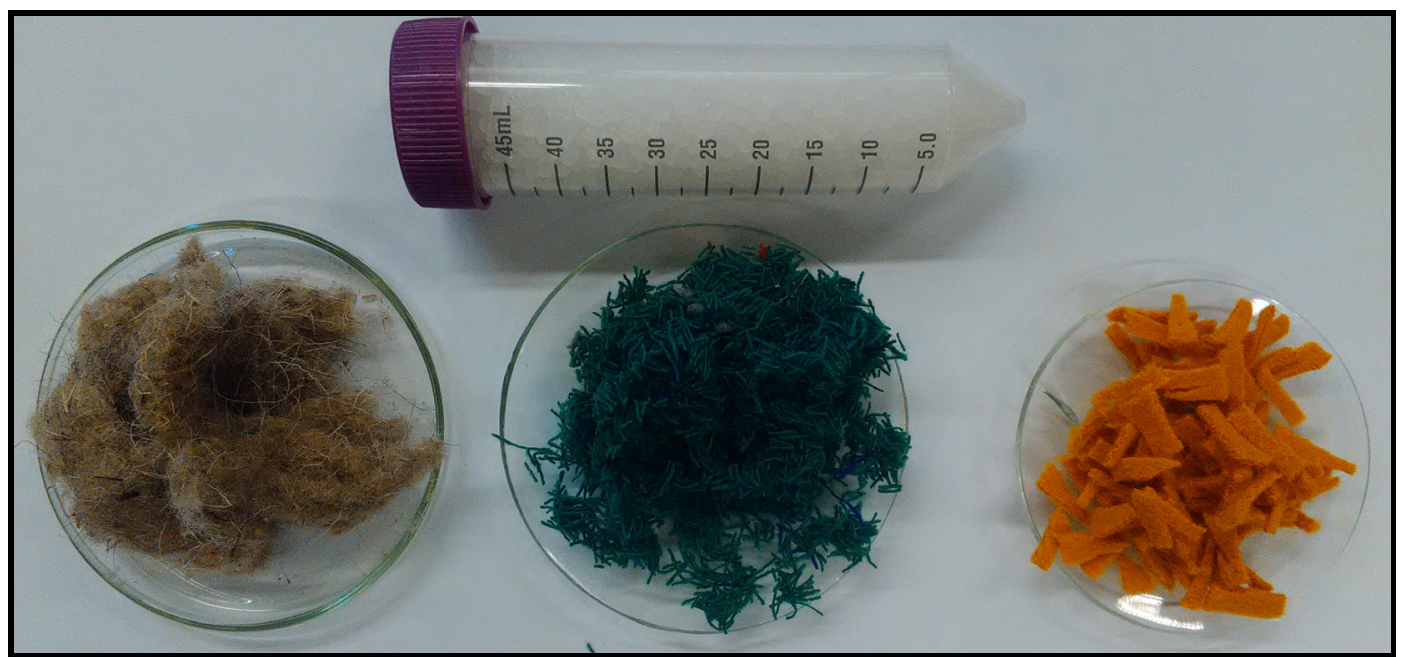

Figure 2 - Portion of cards, yards and felt cloths after being separated and cut.

After sieving, the wood particles residues present the global appearance shown in Fig. 3. The fraction of the Fine particles represents around $50 \%$ of the whole sample, as determined with two batches that were supplied at different times. The respective size distribution is shown in Fig. 4.

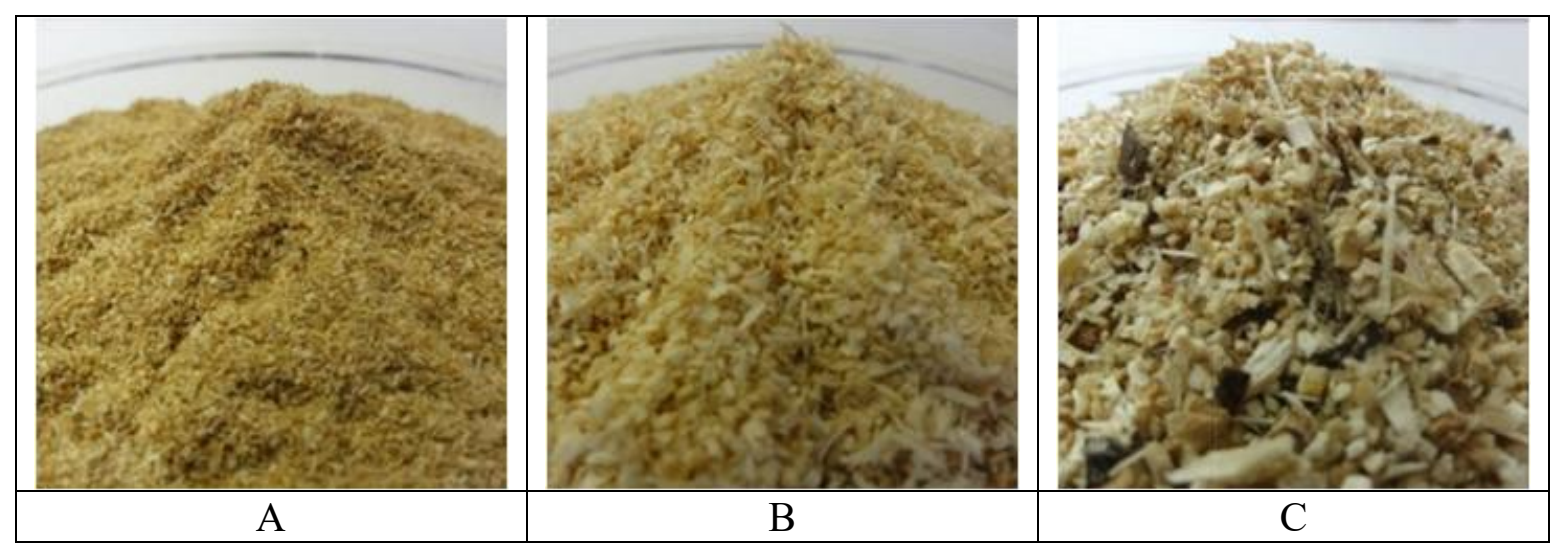

Figure 3 - Pine sawdust after sieving: Fine (A), Medium (B) and Coarse (C) wood particles.

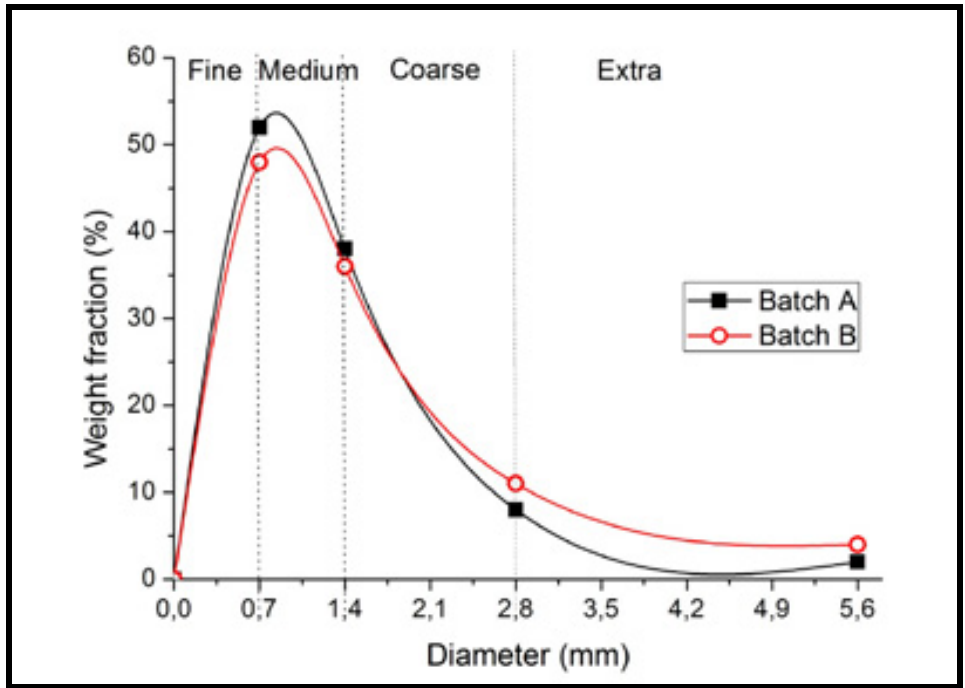

Figure 4 - Particle size distribution of different batches (A and B) of pine wood residues. 
Chemical composition of the wool fibres, wood particles and polymers. The FTIR-ATR spectra of the wool and of the wood samples are depicted in Fig. 5.

The spectra from the cards and felt cloths are almost coincident in the range $500-2000 \mathrm{~cm}^{-1}$ and show some differences in the intensity of the bands around $2800 \mathrm{~cm}^{-1}$. The bands at 1530 and $1630 \mathrm{~cm}^{-1}$ are typically originated by Amide II and Amide I vibrations respectively, indicating that these samples possess a protein character.

On the other hand, the spectrum from the yarns has the same Amide I and II bands, the peak at $1036 \mathrm{~cm}^{-1}$ has higher relative intensity and the band around $2800 \mathrm{~cm}^{-1}$ are similar to those of the cards. However, new peaks are also observed, namely at 718,1245 and $1730 \mathrm{~cm}^{-1}$. This may be interpreted as resulting from the presence of an unexpected component in addition to the wool fibres. It may be a polyester fibre but further analyses are required.

It should be mentioned that these results motivated the repetition of FTIR spectra with other yarns from this type of wool residues. These showed that the chemical composition of the yarns may be coincident to that of the other wool samples, or contain diverse ratios of another component.

As for the wood particles composition, its spectrum has a very intense and broad band at $1036 \mathrm{~cm}^{-1}$, typical from cellulosic materials. It also reveals the presence of lignin due to the bands at 1511 and $1628 \mathrm{~cm}^{-1}$.

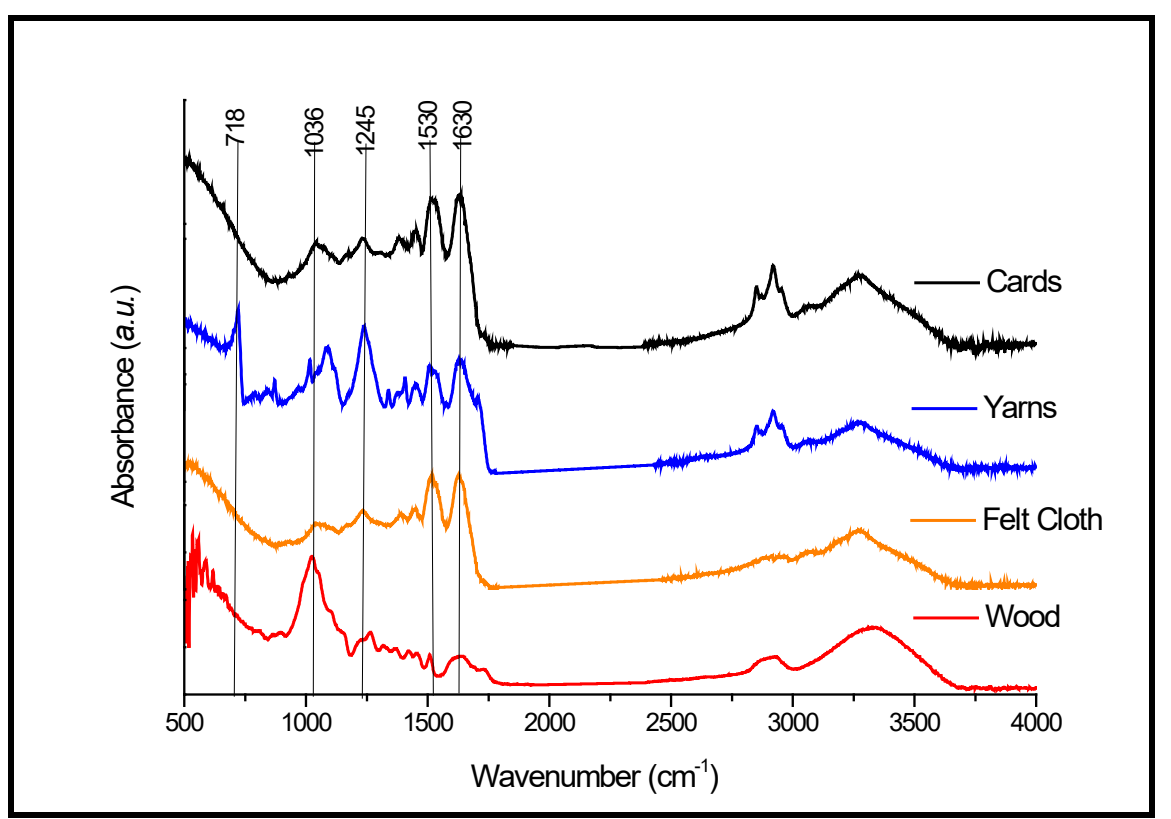

Figure 5 - FTIR spectra of the wool (cards, yarns and felt cloths) fibres and of the wood particles.

The Vibrational spectra of the composites selected for the matrices of the composites are presented in Fig. 6. The spectrum of the polymer derived from potato starch is much more complex than those of the aliphatic polymers, as expected. Whereas the first has numerous bands from the polysaccharide footprint, such as those at around 720,1040 and $1250 \mathrm{~cm}^{-1}$, as well as a very intense band from carbonyl groups at $1730 \mathrm{~cm}^{-1}$. PP and HDPE present simple spectra where the most intense bands, observed in the $2700-3000 \mathrm{~cm}^{-1}$ range, are originated from $\mathrm{C}-\mathrm{H}$ elongation modes of the $-\mathrm{CH}_{2}$ and $-\mathrm{CH}_{3}$ groups. 


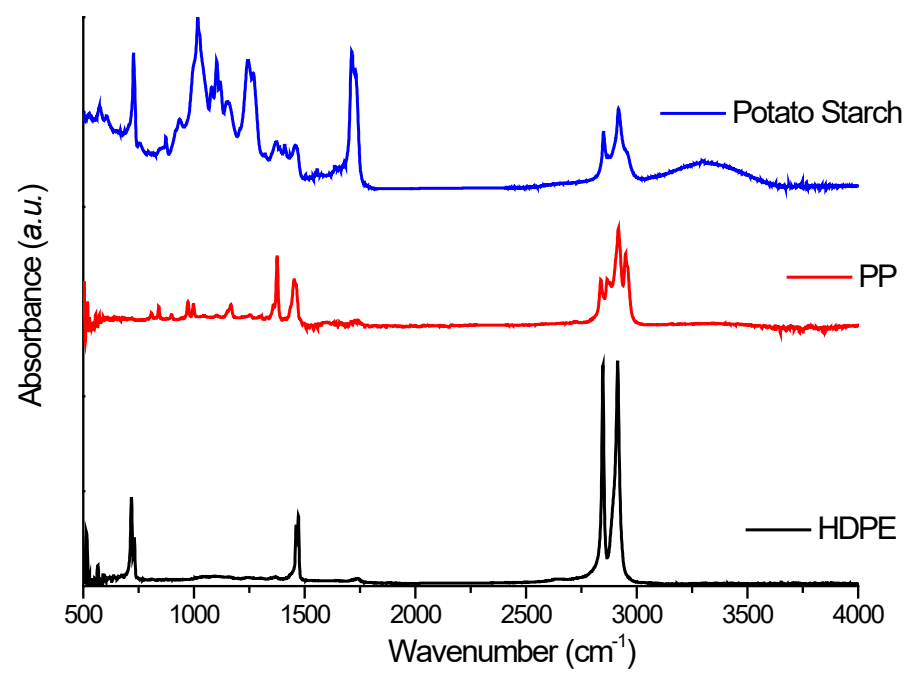

Figure 6 - FTIR spectra of the polymers selected for the composites matrices: a biopolymer based on potato starch, polypropylene and hgh density polyethylene.

Microstructure of the wool fibres and of the wood particles. The microstructure and organization of the selected fibre residues (cards, yarns, felt cloths and wood particles) was observed by SEM at diverse magnifications, as depicted in Fig. 7, 8, 9 and 10 respectively.

The cards show randomly oriented fibres, separated from each other. The diameter of the fibres measures between 3 and $20 \mu \mathrm{m}$, approximately. The surface of the fibres presents some roughness that is due to multiple scales partially overlapped, as observed in greater detail.

The images from the yards correspond to a longitudinal part of twisted strands. This explains why the fibres are aligned and tightly grouped. The diameter of these fibres is more homogeneous, measuring around $10 \mu \mathrm{m}$.

The top surface of the felt cloth presents randomly oriented fibres that have different diameters between 3 and $20 \mu \mathrm{m}$, approximately. Their surface possesses the typical scales, sometimes with some structural damages. These may derive from the felting process that may involve not only chemical, but also mechanical procedures. The structure of interlocked scales, often described as characteristic of felt fabrics, is not observed. A possible explanation is the fact that the observation of the cloth was made over its flat surface and the depth of the electronic beam could not be enough.

The wood particles have a homogeneous size distribution, with sizes inferior to $1 \mathrm{~mm}$ as expected from the use of the sieved sample classified as Fine. The shape and volume of the particles is very heterogeneous, depending on the fragmentation sites. These particles show the traditional structure of wood, with hollow lumen spaces visible in the cross-section and numerous pits across longitudinal areas. These porous structures are involved on the transport of nutrients in the tree.

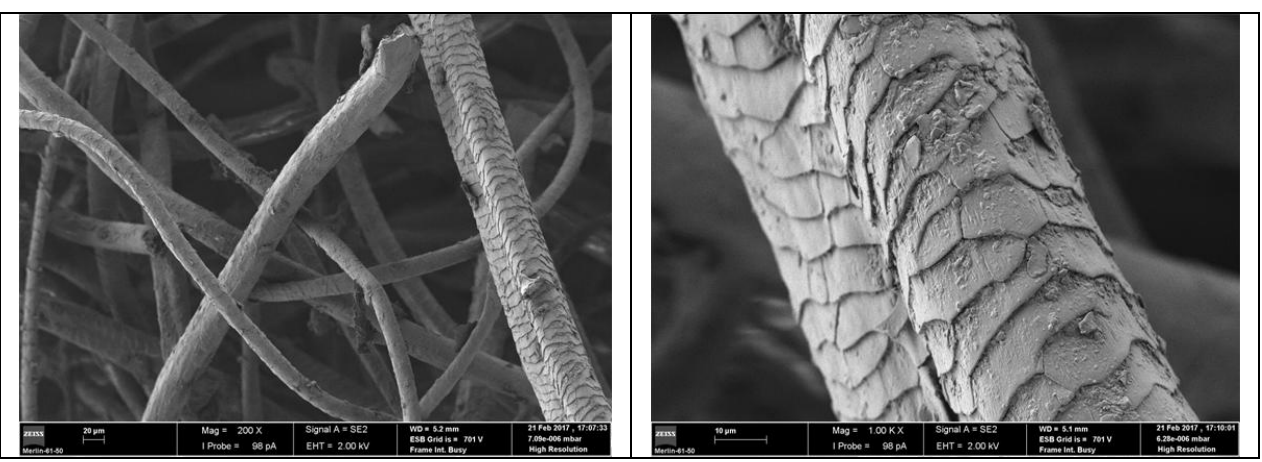

Figure 7 - Microstructure of the cards. 


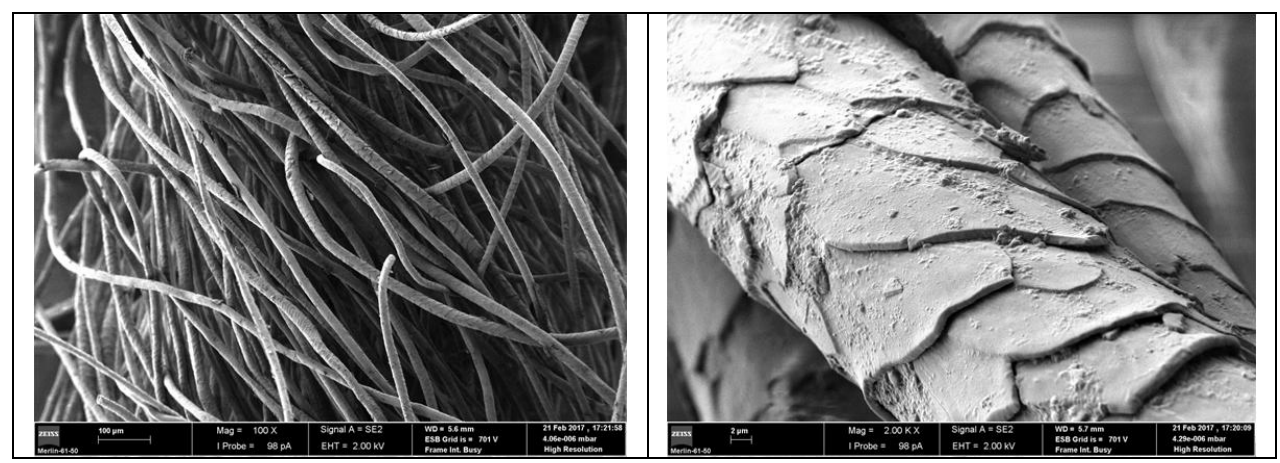

Figure $8-$ Microstructure of the yarns.

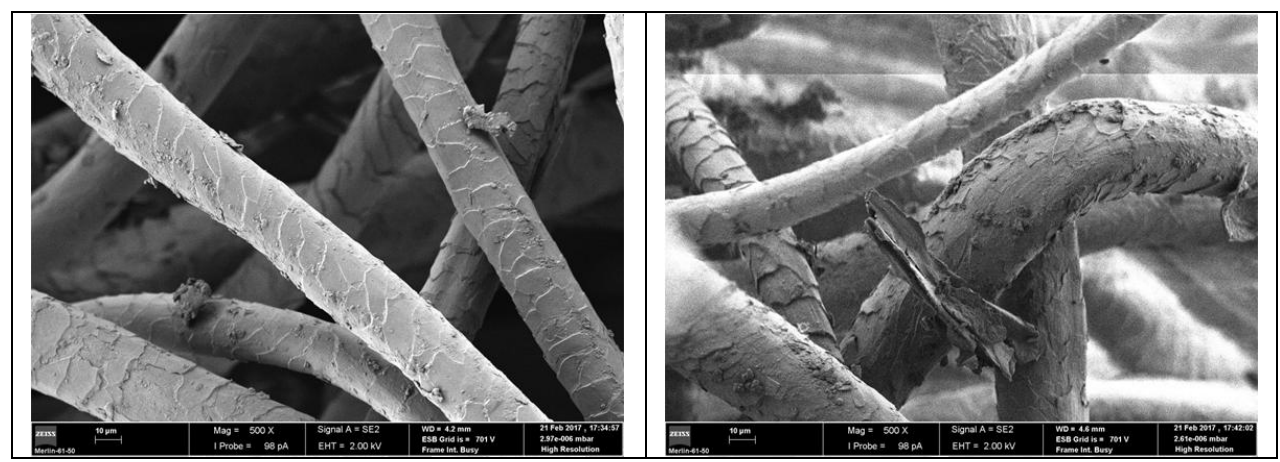

Figure 9 - Microstructure of the felt cloths.

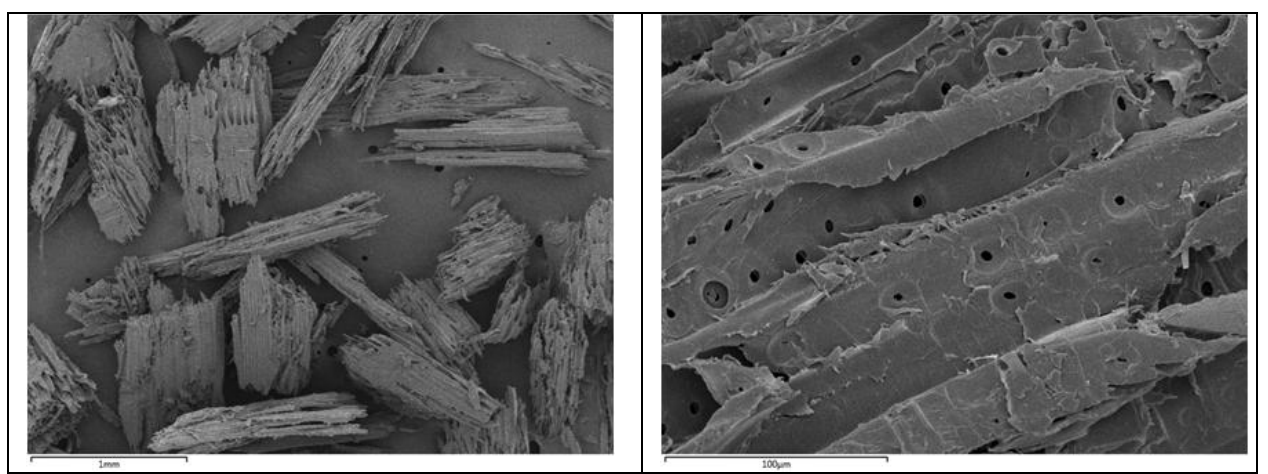

Figure 10 - Microstructure of the pine wood particles (sawdust).

Composites. Macrostructure. The appearance of some of the prepared composites is presented in Fig. 11. The qualitative information regarding the chemical composition is the following:

A - Potato starch + yarns

$\mathrm{B}-$ Potato starch + yarns + sawdust + EVA-co-MA

$\mathrm{C}-\mathrm{PP}+$ cards + sawdust

$\mathrm{D}-\mathrm{HDPE}+$ cards + sawdust + PE-co-MA

$\mathrm{E}-\mathrm{HDPE}+$ yarns + sawdust

$\mathrm{F}-\mathrm{HDPE}+$ felt cloth + sawdust + PE-co-MA

The composites colour derives from that of the wool fibres combined with the light brown from the sawdust. The exception is only composite A that does not include wood particles, just wool from blue yarns. The colour modification by the sawdust addition is demonstrated in composite $\mathrm{E}$ which contains similar blue yarns and sawdust. In general, composites made of cards and sawdust are brown, no matter the polymer of the matrix (in case they have no colour, like in this study). The intensity of the composite colour also depends, in large part, of the processing temperature, the time consumed and the resistance to thermal degradation of each kind of fibres. Regarding the surface of the composites, $\mathrm{A}, \mathrm{B}$ and $\mathrm{F}$ are those with smoother and brighter properties. 


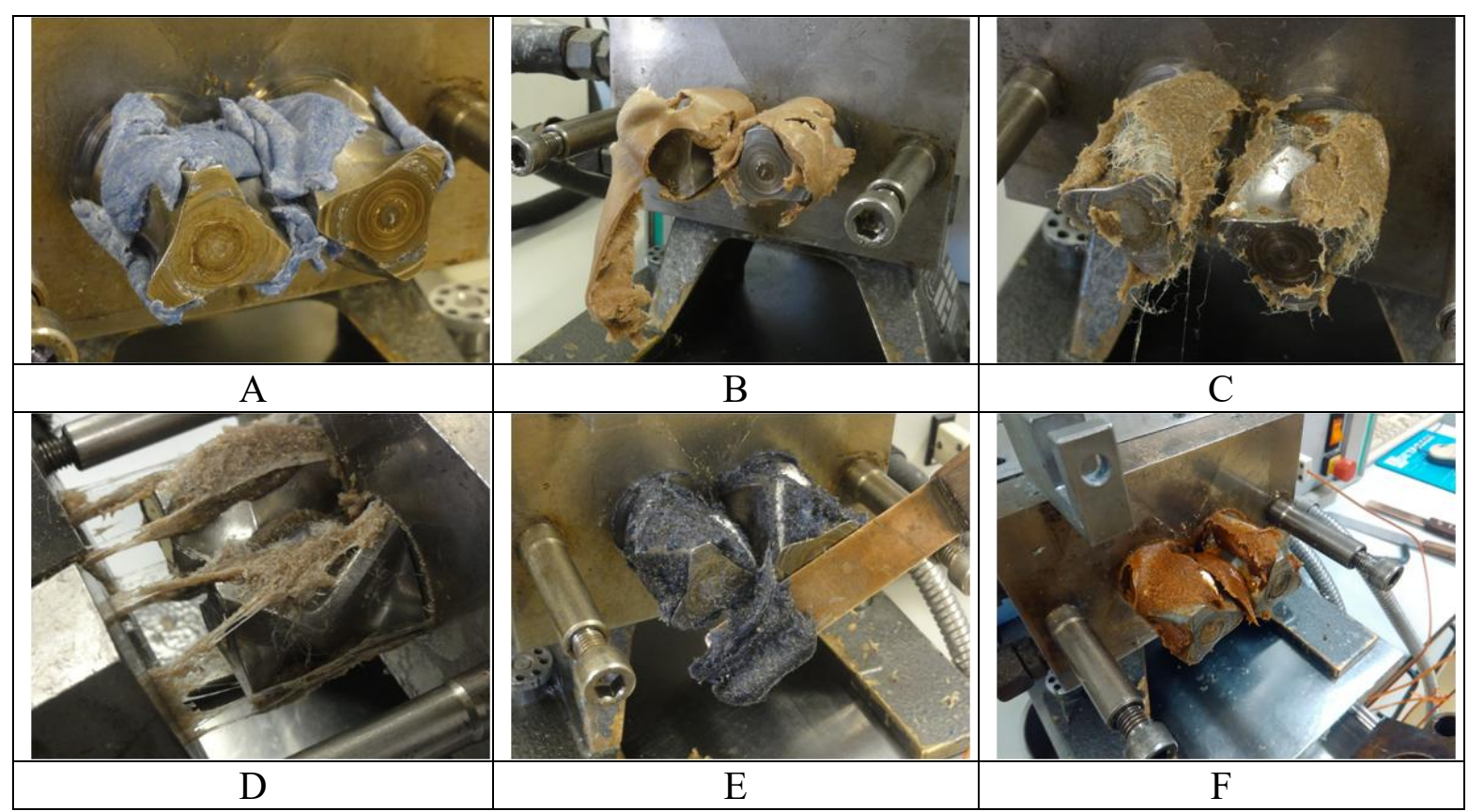

Figure 11 - Composites of different compositions, at the end of the synthesis process.

Microstructure. The microstruture of composites A, C, D and F was observed by SEM. Representative images of the structural details are presented in Figs 12 to 15, respectively.

Composite A was prepared just with potato starch derived polymer and yarns, being the fibres in excessive concentration considering the objective of obtaining suitable viscosity for extrusion or injection molding. The images show that the yarns are homogeneously dispersed across the matrix and the fibres were not damaged after melt blending. They show also that the fracture of the composite was influenced by the flexibility of the polymer and of the yarns.
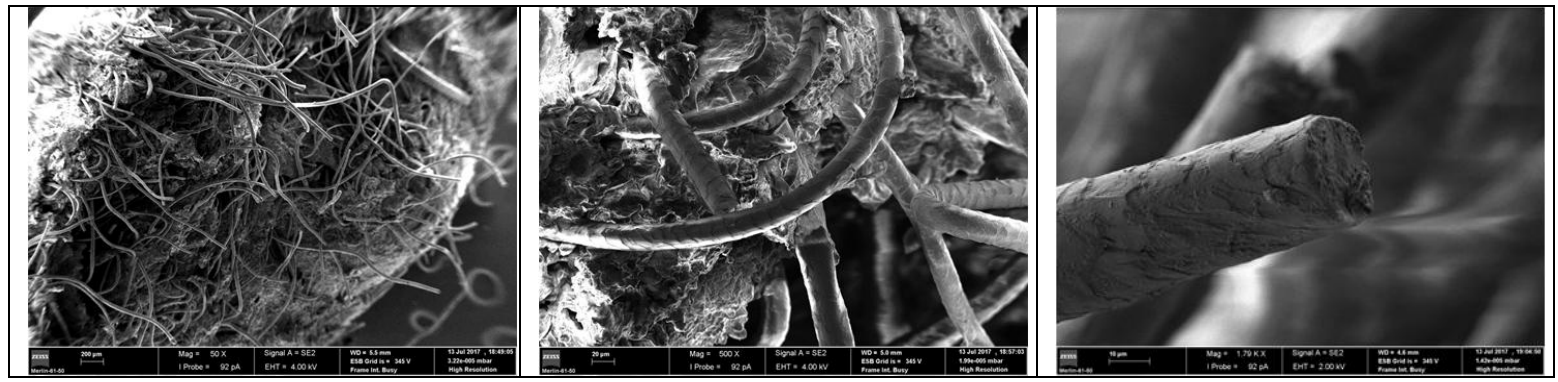

Figure 12 - Microstructure of the composite A.

As for composite $\mathrm{C}$, made of PP, cards and sawdust, the resulting material is brittle. This explains the sharp appearance of the fractured section. The obtained images show agglomerates of cards separated from the wood particles. Some wool fibres appear pulled out of the matrix, indication that their interfacial adhesion with PP is weak. Equivalent conditions are also observed regarding the wood particles. Overall, the weak interactions between all components may influence the mechanical performance of this composite.
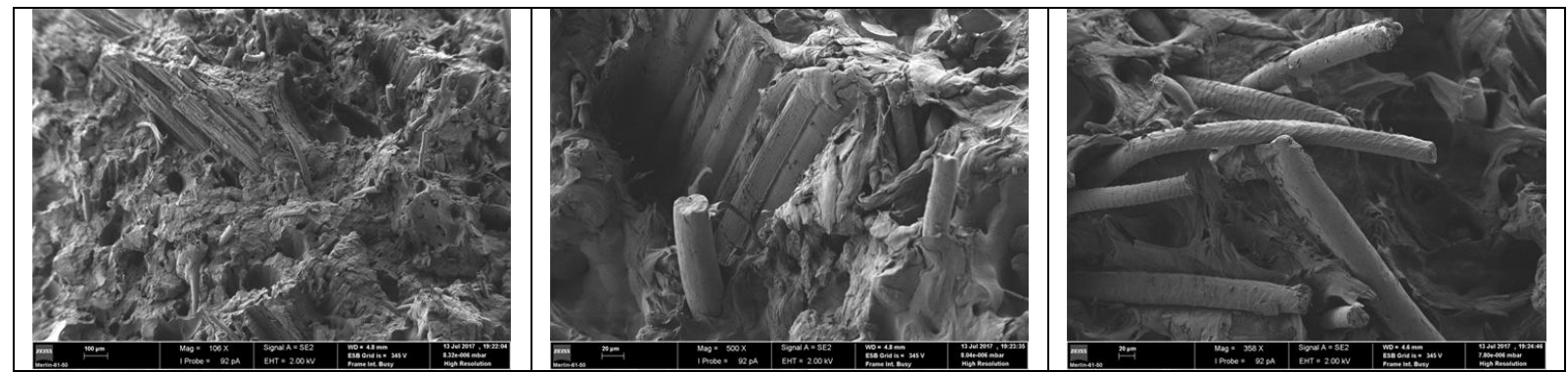

Figure 13 - Microstructure of the composite C. 
Composites D and F are both composed of HDPE, sawdust and wool fibres (cards or felt cloths) and also a coupling agent to enhance the compatibility between such dissimilar components. These composites break through similar mechanisms and the fractured surface is not as sharp as that of composite C. In both cases, the exposed wool fibres and wood particles present material bonds with the respective polymeric matrix, indicating a strong interfacial adhesion and suggesting good mechanical properties. The obtained images are also important to determine that the felt cloths are defibrillated during melt blending, at least under the processing conditions of this study.

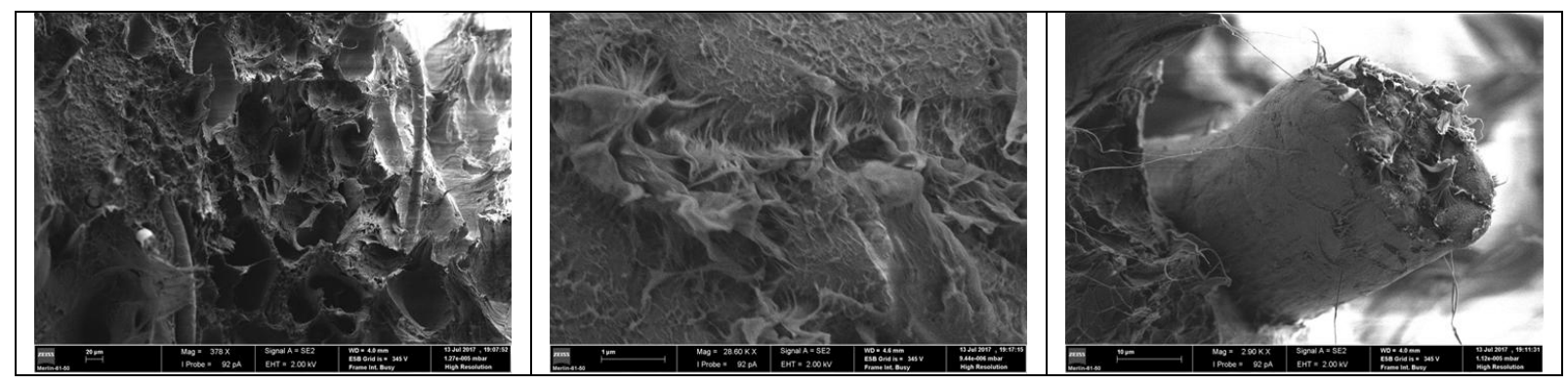

Figure 14 - Microstructure of the composite D.
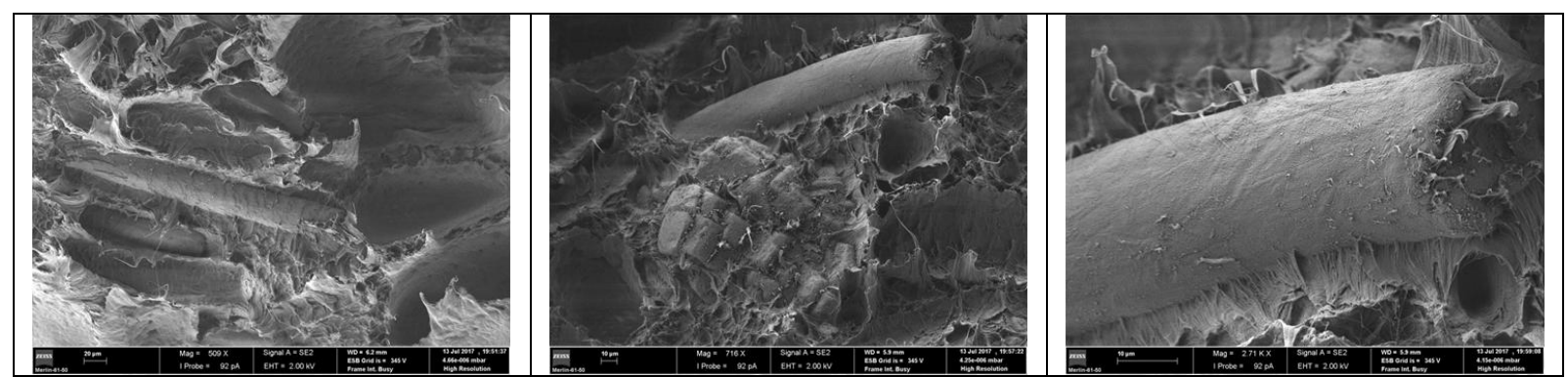

Figure 15 - Microstructure of the composite F.

\section{Conclusions}

The results illustrate the importance of defining screening criteria for the raw materials, particularly when these correspond to residues or waste materials, as the wool and wood fibres supplied for this study. The separation of the fibres was made based on their physical appearance and chemical composition. The FTIR spectra of the bobbins yarns showed that some strands were not exclusively composed of wool, but possibly also contained polyester components. The respective synthetic fibres, that would have a smooth surface, were not observed in SEM images. The characteristic scales of the wool fibres were observed in all samples from the textile industry. However, in the felt cloth, the expected effect of interlocked scales was not evidenced. As for the wood particles, the sieved sample showed a uniform size distribution and the characteristic features of this material, including its vibrational spectrum. The FTIR analysis of the polymers allowed the clear distinction of the natural origin biopolymer based on potato starch from the aliphatic hydrocarbon synthetic polymers.

The synthesis of the composites was performed using variable ratios of wool, wool and two coupling agents based in maleic anhydride grafted polymers. The final appearance of the composites was presented, with comments explaining the observed colours. Depending on the colour of the raw materials, the colour and tonality of the composites may be altered. It may be sated that the wood fibres did not degrade significantly with temperature, or else the composites would be darker. This may be due to a synergistic effect of protection from the wool fibres.

The microstrutural analysis of the composites showed that the most brittle was based on PP, and its components were not tightly linked to each other. This may be due to the absence of any coupling agent. On the other hand, the composite systems with HDPE and PE-co-MA presented not only a homogeneous fibre distribution in the matrix, but also strong adhesion between all 
components. Finally, it was observed that after preparation of the composite, the felt cloth was no longer in the shape of small pieces of fabrics. Defibrillation occurred during the blending process through appropriate effect of the blades rotation and temperature.

\section{Acknowledgements}

The authors are grateful to FEDER - Fundo Europeu de Desenvolvimento Regional, in the aim of COMPETE 2020 with the copromotional project WOWW - World of Outstanding Wool and Wood and to Portuguese Foundation for Science and Technology (FCT) through the Project reference UID/Multi/04044/2013 and PAMI - ROTEIRO/0328/2013 ( ${ }^{\circ}$ 022158).

The authors gratefully acknowledge the contribution to language revision of Dr Sonia Fiuza.

The Coimbra Chemistry Centre, CQC, supported by FCT, through the project PEstOE/QUI/UI0313/2013 is also acknowledged

\section{References}

[1] R. Geyer, J.R. Jambeck, K.L. Law, Production, use, and fate of all plastics ever made, Sci. Adv. 3 (2017) e1700782. doi:10.1126/sciadv.1700782.

[2] L.C.M. Lebreton, J. van der Zwet, J.-W. Damsteeg, B. Slat, A. Andrady, J. Reisser, River plastic emissions to the world's oceans, Nat. Commun. 8 (2017) 15611. doi:10.1038/ncomms15611.

[3] S.M. El Haggar, M.A. Kamel, Wood Plastic Composites, in: Adv. Compos. Mater. - Anal. Nat. Man-Made Mater., 2009: pp. 325-344.

[4] M.P. Wolcott, A technology review of WPC, 33rd Int. Part. Mater. Symp. (1999) 103-111.

[5] F.P. Mantia, M. Morreale, Green composites: A brief review, Compos. Part A Appl. Sci. Manuf. 42 (2011) 579-588.

[6] A.K. Bledzki, J. Gassan, Composites reinforced with cellulose based fibres, Prog. Polym. Sci. 24 (1999) 221-274.

[7] A. Ashori, Wood-plastic composites as promising green-composites for automotive industries!, Bioresour. Technol. 99 (2008) 4661-4667. doi:10.1016/j.biortech.2007.09.043.

[8] O. Faruk, A.K. Bledzki, H.-P. Fink, M. Sain, Progress Report on Natural Fiber Reinforced Composites, Macromol. Mater. Eng. 299 (2014) 9-26. doi:10.1002/mame.201300008.

[9] U.S. Bongarde, V.D. Shinde, Review on natural fiber reinforcement polymer composites, Int. J. Eng. Sci. Innov. Technol. 3 (2014) 431-436.

[10] L. Mohammed, M.N.M. Ansari, G. Pua, M. Jawaid, M.S. Islam, A Review on Natural Fiber Reinforced Polymer Composite and Its Applications, Int. J. Polym. Sci. 2015 (2015) 1-15. doi:10.1155/2015/243947.

[11] L.W. Gallagher, A.G. McDonald, The effect of micron sized wood fibers in wood plastic composites, Maderas. Cienc. Y Tecnol. 15 (2013) 0-0. doi:10.4067/S0718221X2013005000028.

[12] S. Migneault, A. Koubaa, F. Erchiqui, A. Chaala, K. Englund, C. Krause, M. Wolcott, Effect of fiber length on processing and properties of extruded wood-fiber/HDPE composites, J. Appl. Polym. Sci. 110 (2008) 1085-1092. doi:10.1002/app.28720.

[13] G. Martins, F. Antunes, A. Mateus, S. Baptista, C. Malça, Optimization of a wood plastic composite to produce a new dynamic shading system, in: Nat. Fibres Adv. Sci. Technol. Towar. Ind. Appl., RILEM Bookseries, 2016: pp. 343-350. doi:10.1007/978-94-017-7515-1. 
[14] G. Siqueira, J. Bras, A. Dufresne, Cellulosic bionanocomposites: A review of preparation, properties and applications, Polymers (Basel). 2 (2010) 728-765. doi:10.3390/polym2040728.

[15] L. Gil, Cork composites: A review, Materials (Basel). 2 (2009) 776-789. doi:10.3390/ma2030776.

[16] C.-S. Wu, Preparation and Characterizations of Polycaprolactone/ Green Coconut Fiber Composites, J Appl Polym Sci. 115 (2010) 948-956. doi:10.1002/app.

[17] A.W.M. Kahar, H. Ismail, High-density polyethylene/natural rubber blends filled with thermoplastic tapioca starch: Physical and isothermal crystallization kinetics study, J. Vinyl Addit. Technol. 22 (2016) 191-199. doi:10.1002/vnl.21422.

[18] S.S. Ray, Environmentally Friendly Polymer Nanocomposites: Types, Processing and Properties, Woodhead Publishing, U. K., 2013.

[19] D.E. Pendleton, T. a Hoffard, T. Adcock, B. Woodward, M.P. Wolcott, Durability of an extruded HDPE/wood composite, For. Prod. J. 52 (2002) 21-27.

[20] G. Martins, F. Antunes, A. Mateus, C. Malça, Optimization of a Wood Plastic Composite for Architectural Applications, Procedia Manuf. $12 \quad$ (2017) 203-220. doi:10.1016/j.promfg.2017.08.025.

[21] Q. Wang, R. Ou, X. Shen, Y. Xie, Plasticizing cell walls as a strategy to produce woodplastic composites with high wood content by extrusion processes, BioResources. 6 (2011) 3621-3622.

[22] S.K. Yeh, S. Agarwal, R.K. Gupta, Wood-plastic composites formulated with virgin and recycled ABS, Compos. Sci. Technol. $69 \quad$ (2009) 2225-2230. doi:10.1016/j.compscitech.2009.06.007.

[23] M. Pracella, M.M.U. Haque, V. Alvarez, Functionalization, compatibilization and properties of polyolefin composites with natural fibers, Polymers (Basel). 2 (2010) 554-574. doi:10.3390/polym2040554.

[24] G. Cicala, G. Cristaldi, A. Latteri, Composites Based on Natural Fibre Fabrics, Woven Fabr. Eng. (2010) 317-342. doi:10.5772/10465.

[25] J. Feng, Q. Shi, Y. Chen, X. Huang, Mold Resistance and Water Absorption of Wood/HDPE and Bamboo/HDPE Composites, J. Appl. Sci. 14 (2014) 776-783. doi:10.3923/jas.2014.776.783.

[26] K. Klouda, Composite Nanofibers: Polymer-Wood Dust (Green Composites), J Mat Sci Eng A. 3 (2013) 659-666.

[27] S.H. Lee, Y. Teramoto, T. Endo, Cellulose nanofiber-reinforced polycaprolactone/ polypropylene hybrid nanocomposite, Compos. Part A Appl. Sci. Manuf. 42 (2011) 151-156. doi:10.1016/j.compositesa.2010.10.014.

[28] S. Migneault, A. Koubaa, F. Erchiqui, A. Chaala, K. Englund, M.P. Wolcott, Effects of processing method and fiber size on the structure and properties of wood-plastic composites, Compos. Part A Appl. Sci. Manuf. 40 (2009) 80-85. doi:10.1016/j.compositesa.2008.10.004.

[29] H. Bouafif, A. Koubaa, P. Perré, A. Cloutier, Effects of fiber characteristics on the physical and mechanical properties of wood plastic composites, Compos. Part A Appl. Sci. Manuf. 40 (2009) 1975-1981. doi:10.1016/j.compositesa.2009.06.003. 
[30] H. Balakrishnan, M.R. Husin, M.U. Wahit, M.R. Abdul Kadir, Maleated High Density Polyethylene Compatibilized High Density Polyethylene/Hydroxyapatite Composites for Biomedical Applications: Properties and Characterization, Polym. Plast. Technol. Eng. 52 (2013) 774-782. doi:10.1080/03602559.2013.763364.

[31] F.M. Barreiros, A.G. Martins, M. Matos, J. Mascarenhas, M.T. Vieira, Preparing MIM feedstocks for bio-applications using an agar-based binder, Mater. Sci. Forum. 587-588 (2008) 385-389. doi:10.4028/www.scientific.net/MSF.587-588.385.

[32] P. Komposit, P. Termaleik, G. Lalang, K. Penyediaan, Synthesis and Characterisation of Maleated Polypropylene / Lalang Fiber / Polypropelyne Composites: Optimisation Preparation Conditions and Their Properties, 16 (2012) 24-30.

[33] T.J. Keener, R.K. Stuart, T.K. Brown, Maleated coupling agents for natural fibre composites, Compos. Part A Appl. Sci. Manuf. $35 \quad$ (2004) 357-362. doi:10.1016/j.compositesa.2003.09.014.

[34] S. Kalia, B.S. Kaith, I. Kaur, Pretreatments of natural fibers and their application as reinforcing material in polymer composites-a review, Polym. Eng. Sci. 29 (2009) 1253-1272. doi:10.1002/pen.

[35] D. Loof, M. Hiller, H. Oschkinat, K. Koschek, Quantitative and qualitative analysis of surface modified cellulose utilizing TGA-MS, Materials (Basel). 9 (2016) 1-14. doi:10.3390/ma9060415.

[36] B. Unger, M. Bücker, S. Reinsch, T. Hübert, Chemical aspects of wood modification by solgel-derived silica, Wood Sci. Technol. 47 (2013) 83-104. doi:10.1007/s00226-012-0486-7.

[37] M.Y. Abdelaal, E.H. Elmossalamy, S.O.S. Bahaffi, Enhancement of Polyolefins Compatibility with Natural Fibers through Chemical Modification, Am. J. Polym. Sci. 2 (2012) 102-108. doi:10.5923/j.ajps.20120205.04.

[38] J. Cañavate, J. Aymerich, N. Garrido, X. Colom, J. Macanás, G. Molins, M. Álvarez, F. Carrillo, Properties and optimal manufacturing conditions of chicken feathers/poly(lactic acid) biocomposites, J. Compos. Mater. 50 (2016) 1671-1683. doi:10.1177/0021998315595534.

[39] L. Conzatti, F. Giunco, P. Stagnaro, M. Capobianco, M. Castellano, E. Marsano, Polyesterbased biocomposites containing wool fibres, Compos. Part A Appl. Sci. Manuf. 43 (2012) 1113-1119. doi:10.1016/j.compositesa.2012.02.019.

[40] M. Saxena, A. Pappu, Composite Materials from Natural Resources: Recent Trends and Future Potentials, Adv. Compos. Mater. - Anal. Nat. Man-Made Mater. (2011) 121-162.

[41] F. Bertini, M. Canetti, A. Patrucco, M. Zoccola, Wool keratin-polypropylene composites: Properties and thermal degradation, Polym. Degrad. Stab. 98 (2013) 980-987. doi:10.1016/j.polymdegradstab.2013.02.011.

[42] M. Pasha, Characterization of natural fiber (sheep wool)-reinforced composites at different operating conditions, J. Ind. Text. 0 (2014) 1-22. doi:10.1177/1528083714540698.

[43] R. Govindaraju, S. Jagannathan, M. Chinnasamy, P. Kandhavadivu, Optimization of Process Parameters for Fabrication of Wool Fiber-Reinforced Polypropylene Composites with Respect to Mechanical Properties, 9 (2014) 126-133.

[44] J.H. Bradbury, The Morphology and Chemical Structure of Wool, Pure Appl. Chem. 46 (1976). doi:10.1351/pac197646020247.

[45] W.P. Limited, Handbook of textile and industrial dyeing, Woodhead Publishing Limited, 2009. doi:10.1016/B978-1-84569-385-5.50021-0. 
[46] E.S. Wilks, ed., Wool, in: Ind. Polym. Handb. Prod. Process. Appl., Vol 3 Biop, Wiley-VCH, 2001: pp. 2265-2300.

[47] M. Amin Omri, A. Triki, M. Ben Hassen, M. Arous, A. Bulou, Influence of wool and thermo-binder fibers relative fractions on the adhesion of non-woven Alfa fibers reinforced unsaturated polyester hybrid composites, Phys. E Low-Dimensional Syst. Nanostructures. 84 (2016) 316-323. doi:10.1016/j.physe.2016.07.014.

[48] C. Santulli, F. Sarasini, J. Tirillò, T. Valente, M. Valente, a. P. Caruso, M. Infantino, E. Nisini, G. Minak, Mechanical behaviour of jute cloth/wool felts hybrid laminates, Mater. Des. 50 (2013) 309-321. doi:10.1016/j.matdes.2013.02.079.

[49] J.H. Johnston, F.M. Kelly, J. Moraes, T. Borrmann, D. Flynn, Conducting polymer composites with cellulose and protein fibres, Curr. Appl. Phys. 6 (2006) 587-590. doi:10.1016/j.cap.2005.11.067.

[50] G. Rajkumar, J. Srinivasan, L. Suvitha, Development of novel silk/wool hybrid fibre polypropylene composites, Iran. Polym. J. (English Ed. 22 (2013) 277-284. doi:10.1007/s13726-013-0128-4.

[51] J. Korol, D. Burchart-Korol, M. Pichlak, Expansion of environmental impact assessment for eco-efficiency evaluation of biocomposites for industrial application, J. Clean. Prod. 113 (2016) 144-152. doi:10.1016/j.jclepro.2015.11.101. 